\title{
Myocardial infarction patients show altered lipoprotein properties and functions when compared with stable angina pectoris patients
}

\author{
Kyung-Hyun Cho, ${ }^{1,4}$, Dong-Gu Shin ${ }^{2}$, \\ Suk-Hwan Baek ${ }^{3}$ and Jae-Ryong $\mathrm{Kim}^{3}$ \\ ${ }^{1}$ School of Biotechnology \\ Aging-associated Vascular Disease Research Center \\ Yeungnam University \\ Gyeongsan 712-749, Korea \\ ${ }^{2}$ Cardiovascular Division, Internal Medicine \\ Yeungnam University Medical Center \\ Daegu 705-717, Korea \\ ${ }^{3}$ Department of Biochemistry and Molecular Biology \\ Aging-associated Vascular Disease Research Center \\ Yeungnam University \\ Daegu 705-717, Korea \\ ${ }^{4}$ Corresponding author: Tel, 82-53-810-3026; \\ Fax, 82-53-814-3026; E-mail, chok@yu.ac.kr \\ DOI 10.3858/emm.2009.41.2.009
}

Accepted 16 October 2008

Abbreviations: ACS, acute coronary syndrome; AP, angina pectoris; $\mathrm{BMI}$, body mass index; MI, myocardial infarction; TG, triacylglycerol

\begin{abstract}
Several parameters and risk factors were compared between Korean male myocardial infarction (MI) patients $(n=10)$ and angina pectoris (AP) patients ( $n=$ 17) to search unique biomarkers for myocardial infarction (MI) in lipoprotein level. Individual serum and lipoprotein fractions (VLDL, LDL, $\mathrm{HDL}_{2}, \mathrm{HDL}_{3}$ ) were isolated and analyzed by lipid and protein determination and enzyme assay. The MI group was found to have a $\mathbf{2 5}$ and $\mathbf{3 0} \%$ higher serum cholesterol and triacylglycerol (TG) level than the AP group, respectively, however, their body mass index (BMI), LDL-cholesterol (C), HDL-C, and glucose levels fell within the normal range. Ml patients were found to have an approximately two-fold higher level of serum IL-6 and an 18\% lower serum apoA-I level than that of the AP group. LDL and $\mathrm{HDL}_{2}$ fraction of the Ml group were more enriched with TG than those of AP group. The increased TG was correlated well with the increased level of apoC-III in the same fraction. Cholesteryl ester transfer protein (CETP) activity and protein level were greatly increa-
\end{abstract}

sed in Ml patients in the LDL and $\mathrm{HDL}_{3}$ fractions. Ml patients showed more severely oxidized LDL fraction than patients in the AP group, as well as the weakest antioxidant ability of serum. Conclusively, Ml patients were found to have unique serum and lipoprotein characteristics including increased IL- 6 and TG in serum, with CETP and apoC-III in the LDL and HDL fractions, as well as severely impaired antioxidant ability of HDL.

Keywords: angina pectoris; biological markers; cholesteryl ester transfer protein; inflammation; interleukin-6; lipoproteins; myocardial infarction

\section{Introduction}

Coronary heart disease (CHD) is responsible for the vast majority of cases of unstable angina, acute myocardial infarction (MI), and sudden death. $\mathrm{MI}$ is an acute and catastrophic event that results from acute coronary syndrome (ACS) and atherosclerosis, which chronically progresses to ACS (Thygesen et al., 2007). Myocardial infarction is a leading cause of morbidity and mortality in adults in western countries and Asia (Rosamond et al., 2007), and diagnostic biomarkers for MI such as serum levels of glutamic oxaloacetic transaminase (GOT), lactate dehydrogenase (LDH), creatine kinase (CK)-MB, and troponin I and T have been developed and utilized clinically (Jaffe et al., 2000). However, the aforementioned markers are limited because they provide insufficient specificity for predictive Ml diagnosis. Additionally, although several biomarkers have been reported to predict cardiovascular risk, there have been no useful biomarkers developed for the early detection of $\mathrm{MI}$ (Pahor et al., 1999). Inflammation is a major risk factor of atherosclerosis, and several inflammatory biomarkers such as high sensitivity C-reactive protein (hsCRP), cytokines, biomarkers of endothelial cell activation, and proinflammatory enzymes have been established for the diagnosis of ACS (Hartford et al., 2007); however, no studies have been reported to determine if these biomarkers are useful for the prediction of acute Ml.

There have been many noninvasive biochemical measures used to predict cardiovascular risk, such 
as lipid and lipoprotein metabolism, inflammation, and oxidative stress (Tsimikas, 2006; Thygesen et al., 2007; Walldius et al., 2007). However, it is necessary to develop more readily available specific and prognostic biomarkers that allow MI to be distinguished from AP. Because $\mathrm{MI}$ is a major cause of sudden death and disability worldwide, rapid assays for the early detection of $\mathrm{MI}$ would have widespread application. However, to date, there have been no studies conducted to compare the characteristics of serum and lipoprotein levels of AP and MI patients.

In the current study, the serum parameters, lipoprotein properties, and lipoprotein functions of Korean male MI patients, angina pectoris $(A P)$ patients and sex and age matched normal subjects were compared to determine if distinguished difference could be used for the prognostic biomarkers of MI.

\section{Results}

\section{Serum lipid profile and inflammatory markers}

As shown in Table 1, patients in the MI group were found to have significantly higher levels of serum total cholesterol (TC) and triglyceride (TG) than patients in the other groups, although all patients were found to have a similar BMI. In addition, all participants were found to have similar levels of LDL-C, HDL-C, and glucose, with the exception of those in the MI group, which had the lowest percentage of HDL-cholesterol. Additionally, the serum apoA-I level was significantly decreased by up to $18 \%$ in the $\mathrm{MI}$ group when compared with $\mathrm{AP}$ group, indicating that decreased apoA-I can be a specific marker for ACS, especially in cases of MI.

Inflammatory profiles (Table 2) revealed that patients with AP and MI had hsCRP levels up to

Table 1. Serum lipid profiles of patients and controls. ${ }^{1}$

\begin{tabular}{lccc}
\hline \multicolumn{1}{c}{ Group } & Angina pectoris $(n=17)$ & Myocardial infarction $(n=10)$ & Control $(n=7)$ \\
\hline Age $(\mathrm{yr})$ & $60.6 \pm 9.8$ & $54.5 \pm 10.8$ & $50 \pm 6$ \\
BMl $\left(\mathrm{kg} / \mathrm{m}^{2}\right)$ & $23.5 \pm 2.5$ & $23.9 \pm 2.3$ & $23.8 \pm 2.5$ \\
TC $(\mathrm{mg} / \mathrm{dl})$ & $157 \pm 33^{2, \mathrm{a}}$ & $208 \pm 20^{\mathrm{b}}$ & $168 \pm 15^{\mathrm{a}}$ \\
TG $(\mathrm{mg} / \mathrm{dl})$ & $122 \pm 39^{\mathrm{a}}$ & $175 \pm 49^{\mathrm{b}}$ & $130 \pm 23^{\mathrm{a}}$ \\
LDL-C $(\mathrm{mg} / \mathrm{dl})$ & $106 \pm 30$ & $118 \pm 35$ & $110 \pm 21$ \\
HDL-C $(\mathrm{mg} / \mathrm{dl})$ & $48 \pm 8$ & $54 \pm 13$ & $51 \pm 8$ \\
\% HDL-C & $30 \pm 2^{\mathrm{a}}$ & $25 \pm 3^{\mathrm{b}}$ & $30 \pm 3^{\mathrm{a}}$ \\
apoA-l $(\mathrm{mg} / \mathrm{dl})$ & $148 \pm 25^{\mathrm{a}}$ & $121 \pm 21^{\mathrm{b}}$ & $151 \pm 30^{\mathrm{a}}$ \\
Glucose $(\mathrm{mg} / \mathrm{dl})$ & $149 \pm 53$ & $124 \pm 18$ & $106 \pm 12$ \\
CETP $(\mathrm{mg} / \mathrm{l})$ & $4.0 \pm 0.3^{\mathrm{a}}$ & $4.4 \pm 0.4^{\mathrm{a}}$ & $2.3 \pm 0.3^{\mathrm{b}}$
\end{tabular}

${ }^{1}$ Data were expressed as the mean \pm S.D.

${ }^{2}$ Means in the same row not sharing a common superscript are significantly different $(P<0.05)$ between groups.

BMI, body mass index; CETP, cholesteryl ester transfer protein; HDL-C, high density lipoprotein-cholesterol; LDL-C, low density lipoprotein-cholesterol; LPO, lipid hydroperoxide; TC, total cholesterol; TG, triacylglycerol.

Table 2. Inflammatory profiles of serum. ${ }^{1}$

\begin{tabular}{lccc}
\hline \multicolumn{1}{c}{ Group } & Angina pectoris $(n=17)$ & Myocardial infarction $(n=10)$ & Control $(n=7)$ \\
\hline MPO $(\mathrm{ng} / \mathrm{ml})$ & $9.6 \pm 4.8^{\mathrm{a}, 2}$ & $9.1 \pm 4.6^{\mathrm{a}}$ & $3.2 \pm 0.4^{\mathrm{b}}$ \\
LPO $(\mathrm{nmol} / \mathrm{ml})$ & $8.2 \pm 0.2^{\mathrm{a}}$ & $8.4 \pm 0.1^{\mathrm{a}}$ & $4.3 \pm 0.02^{\mathrm{b}}$ \\
SAA $(\mathrm{mg} / \mathrm{ml})$ & $60.3 \pm 60^{\mathrm{a}}$ & $51.8 \pm 58^{\mathrm{a}}$ & $6.1 \pm 0.5^{\mathrm{b}}$ \\
IL-6 $(\mathrm{pg} / \mathrm{ml})$ & $6.6 \pm 5.4^{\mathrm{a}}$ & $15.6 \pm 4.1^{\mathrm{b}}$ & $0.1^{\mathrm{c}}$ \\
hSCRP $(\mathrm{mg} / \mathrm{dl})$ & $0.7 \pm 0.5^{\mathrm{a}}$ & $0.8 \pm 0.4^{\mathrm{a}}$ & $0.2 \pm 0.05^{\mathrm{b}}$ \\
GOT (U/L) & $23 \pm 5^{\mathrm{a}}$ & $117 \pm 103^{\mathrm{b}}$ & $24 \pm 4^{\mathrm{a}}$ \\
GPT (U/L) & $28 \pm 13$ & $37 \pm 29$ & $33 \pm 18$ \\
LDH (U/L) & $350 \pm 66^{\mathrm{a}}$ & $728 \pm 249^{\mathrm{b}}$ & $422 \pm 62^{\mathrm{a}}$ \\
Troponin I (ng/ml) & $0.04 \pm 0.03^{\mathrm{a}}$ & $30 \pm 13^{\mathrm{b}}$ & - \\
Troponin T $(\mathrm{ng} / \mathrm{ml})$ & $0.01 \pm 0.01^{\mathrm{a}}$ & $4.9 \pm 2.8^{\mathrm{b}}$ & - \\
CK-MB $(\mathrm{ng} / \mathrm{ml})$ & $1.2 \pm 0.5^{\mathrm{a}}$ & $176 \pm 156^{\mathrm{b}}$ & - \\
\hline
\end{tabular}

${ }^{1}$ Data were expressed as the mean \pm S.D.

${ }^{2}$ Means in the same row not sharing a common superscript are significantly different $(P<0.05)$ between groups.

CK-MB, creatine kinase MB; GOT, glutamic oxaloacetic transaminase; GPT, gamma-glutamic pyruvic transaminase; IL-6, interleukin-6;

LDH, lactate dehydrogenase; LPO, lipid hydroperoxide; MPO, myeloperoxidase; SAA, serum amyloid A. 
4-fold higher than control patients, indicating that the hsCRP level can be a marker for coronary artery disease (CAD), but that it is less specific for MI detection. As expected, when compared to patients in the other groups, patients in the MI group had a significantly higher level of markers already established for MI such as CK-MB, troponin $\mathrm{I}$ and $\mathrm{T}, \mathrm{GOT}$, and $\mathrm{LDH}$. Interestingly, patients in the Ml group were found to have the highest level of serum IL-6, 2-fold more than that of AP group, indicating that IL-6 may be a prominent biomarker for MI. However, the serum levels of myeloperoxidase (MPO), lipid hydroperoxide (LPO), and serum amyloid (SAA) were significantly higher in patients in the AP and MI group than the control group, indicating that those parameters may be biomarkers for CAD, but not for MI. Furthermore, there was no difference in the SAA levels of patients in the AP and MI groups, even though the SAA level of both of these groups was found to be 10 -fold higher than that of the control. Moreover, the serum LPO level was approximately 2-fold higher in patients in the AP and MI group than those in the control group, indicating that the LPO level can be a specific marker for CAD including ACS. Taken together, these results indicate that increased serum TG and IL-6 levels can be used as specific biomarkers for the detection of $\mathrm{MI}$ in addition to the traditional biomarkers for MI such as troponin and CK-MB level (Table 2).

\section{TG and apoC-III were increased in lipoproteins from MI}

The lipoprotein levels were evaluated by determining the cholesterol, TG, and protein contents of each of the groups. As shown in Table 3, the LDL-C and LDL-TG levels were increased in the MI group, however, no significant differences in the VLDL fraction were observed among the groups. Interestingly, the $\mathrm{HDL}_{2}-\mathrm{C}$ level was decreased and the $\mathrm{HDL}_{2}$-TG level was higher in the MI group than the AP and control groups, which strongly suggests that an increase in TG in the LDL and HDL fractions could be a highly specific symptom of MI. Furthermore, ELISA-based detection revealed that the apoC-III protein level in the LDL and $\mathrm{HDL}_{2}$ fractions of the MI group was increased by up to $45 \%$ when compared with the levels observed in the AP group (Figure 1A). These increases in the level of apoC-III are well correlated with the increased TG levels observed in the serum (Table 1) and lipoprotein of the MI group, especially in the LDL and HDL fractions (Table 3). Additionally, these results are in good agreement with previous

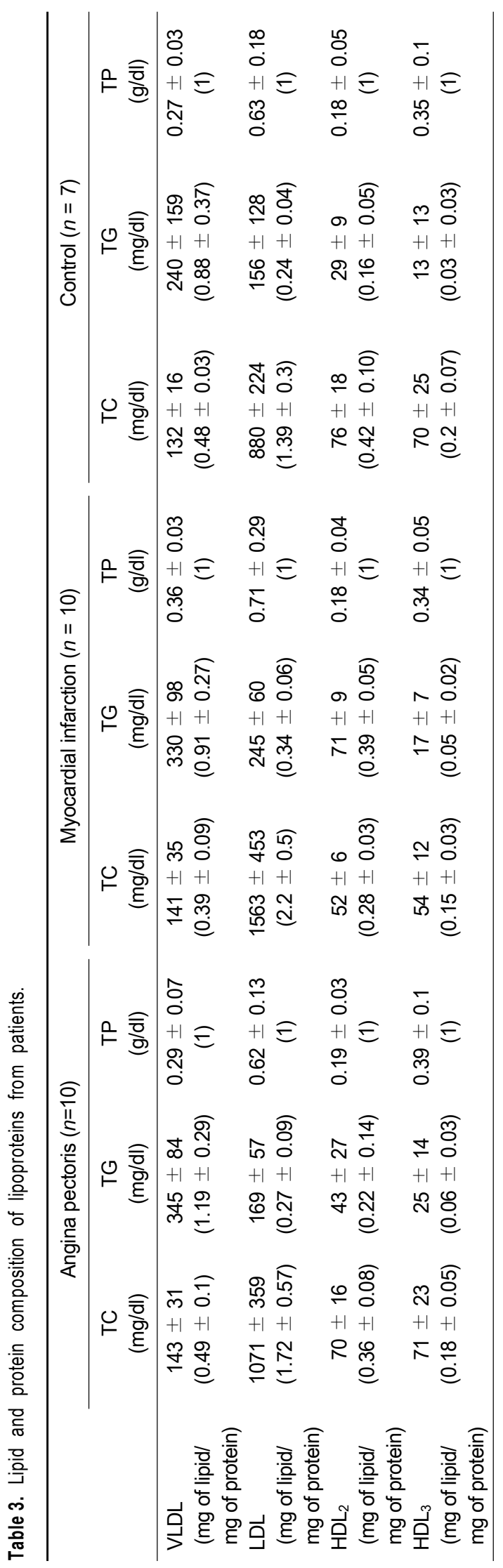


studies that have found plasma TG to be a significant predictor of CAD (Hokanson et al., 1996), as well as with the results of studies that have found high levels of apoC-III in the VLDL and LDL fractions to be a strong significant predictor of coronary events (Sacks et al., 2000). Taken together, these results indicate that increased levels of TG and apoC-III are directly connected with the incidence of MI.

\section{Increase of CETP protein and activity}

In plasma level, the $\mathrm{MI}$ and $\mathrm{AP}$ group showed a higher CE-transfer activity from HDL to LDL than the control group (Table 4). As shown in Table 1, this activity was correlated well with the ELISA based detection, with the serum CETP protein content being increased almost 2-fold when compared to that of the control.

When the lipoprotein levels were considered, the $\mathrm{Ml}$ group showed the highest $\mathrm{HDL}_{3}$-CETP activity, but there was no significant difference in the $\mathrm{HDL}_{2}$-CETP activity between the groups. However, the CETP activity of the LDL fraction was 2-fold higher in the AP and MI group (7-10\% CE-transfer) than in the control group (2.7\% CE-transfer), indicating that LDL-CETP activity in CAD patients was enhanced.

Patients in the MI group had much more CETP protein in the LDL and $\mathrm{HDL}_{3}$ fractions than those in
A

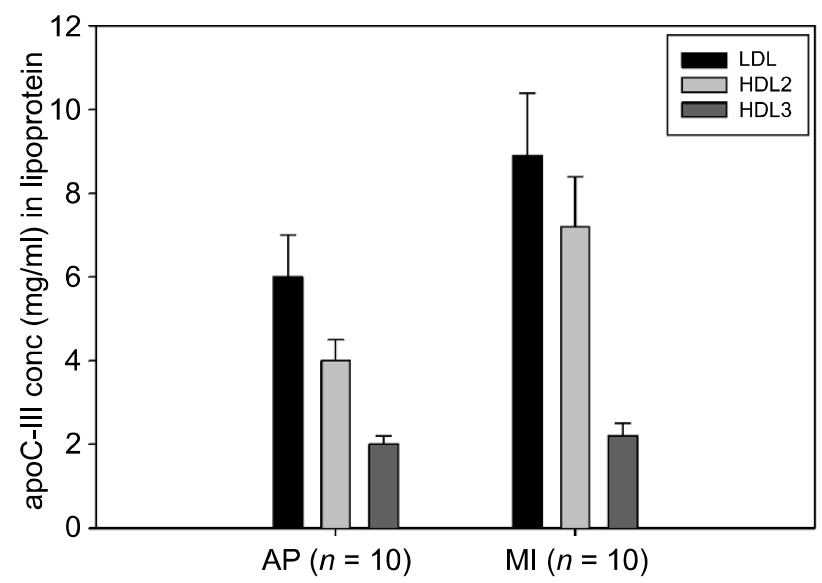

B

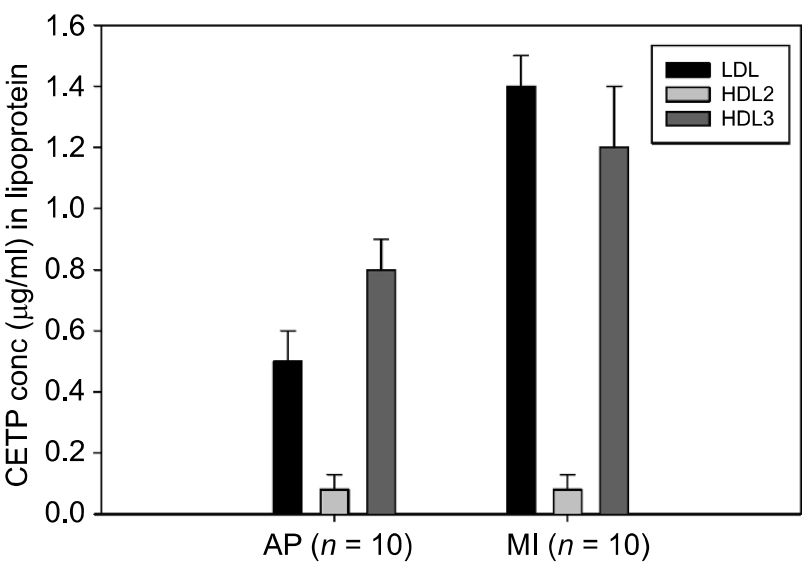

Figure 1. Sandwich ELISA-based detection of apoC-III (panel A) and CETP (panel B) in lipoprotein. Fifty microliters of individual lipoprotein (2 mg of protein/ml) was reacted with polyclonal CETP antibody (Abcam, ab19012) or apoC-III antibody (AB821), which was coated on a 96-well plate. In Ml group, protein levels of apoC-III was highly expressed in both the LDL and $\mathrm{HDL}_{2}$ fraction, while CETP level was increased in $\mathrm{LDL}$ and $\mathrm{HDL}_{3}$ fraction.

Table 4. Lipoprotein-associated enzyme activities. ${ }^{1}$

\begin{tabular}{lcccc}
\hline & Enzyme source & $\begin{array}{c}\text { Angina pectoris } \\
(n=10)\end{array}$ & $\begin{array}{c}\text { Myocardial infarction } \\
(n=10)\end{array}$ & Control $(n=7)$ \\
\hline CETP & $\mathrm{HDL}_{2}$ & $9 \pm 5.1$ & $8.9 \pm 4.7$ & $8.0 \pm 4.6$ \\
(\% CE transfer from [ $\left.{ }^{3} \mathrm{H}\right]-$ & $\mathrm{HDL}_{3}$ & $14.6 \pm 4.7^{\mathrm{a}, 2}$ & $25.4 \pm 3.6^{\mathrm{b}}$ & $10 \pm 2^{\mathrm{a}}$ \\
CE-HDL to LDL/mg of protein) & $\mathrm{LDL}$ & $7.6 \pm 3.3^{\mathrm{a}}$ & $10.3 \pm 2.5^{\mathrm{a}}$ & $2.7 \pm 0.1^{\mathrm{b}}$ \\
& $\mathrm{VLDL}$ & $3.0 \pm 0.4$ & $2.7 \pm 0.6$ & - \\
& $\mathrm{Serum}$ & $29.7 \pm 8.0^{\mathrm{a}}$ & $41.8 \pm 6.3^{\mathrm{b}}$ & $24 \pm 3.3^{\mathrm{c}}$ \\
PLA2 (pmole PAF/h/mg & $\mathrm{LDL}^{\mathrm{m}}$ & $15.5 \pm 0.7^{\mathrm{a}}$ & $15.3 \pm 0.3^{\mathrm{a}}$ & $10.3 \pm 0.6^{\mathrm{b}}$ \\
of protein) & $\mathrm{HDL}_{2}$ & $9.1 \pm 0.5^{\mathrm{a}}$ & $11.8 \pm 1.3^{\mathrm{a}}$ & $29.1 \pm 1.3^{\mathrm{b}}$ \\
& $\mathrm{HDL}_{3}$ & $15.0 \pm 2.4$ & $16.6 \pm 0.9$ & $15.4 \pm 1.4$ \\
PON $(\mu \mathrm{U} / \mathrm{L} / \mathrm{mg}$ of protein) & $\mathrm{HDL}_{3}$ & $179 \pm 69^{\mathrm{a}}$ & $113 \pm 45^{\mathrm{a}}$ & $1671 \pm 70^{\mathrm{b}}$ \\
LCAT (\% CE-conversion/hr/ & $\mathrm{HDL}_{3}$ & $1.8 \pm 1.4^{\mathrm{a}}$ & $3.1 \pm 1.2^{\mathrm{a}}$ & $10.2 \pm 1.2^{\mathrm{b}}$ \\
$100 \mu \mathrm{g}$ of protein & & & & \\
\hline
\end{tabular}

${ }^{1}$ Each assay method was described in text.

${ }^{2}$ Data were expressed as the mean \pm S.D. Means in the same row not sharing a common superscript are significantly different $(P<0.05)$ between groups.

CETP, cholesteryl ester transfer protein; LCAT, lecithin:cholesterol acyltransferase; PLA2, phospholipase A2; PON, paraoxonase. 
the AP group (Figure 1B) from ELISA based detection, while CETP amount in $\mathrm{HDL}_{2}$ was not different between the groups. Taken together, apoC-III and CETP levels were significantly coincreased in LDL fraction of MI group (Figure 1).

\section{Enzyme activities of lipoproteins}

The paraoxonase (PON) and lecithin:cholesterol acetyl transferase (LCAT) activity in the $\mathrm{HDL}_{3}$ fraction was several fold lower in the AP and MI groups than the control group (Table 4), suggesting

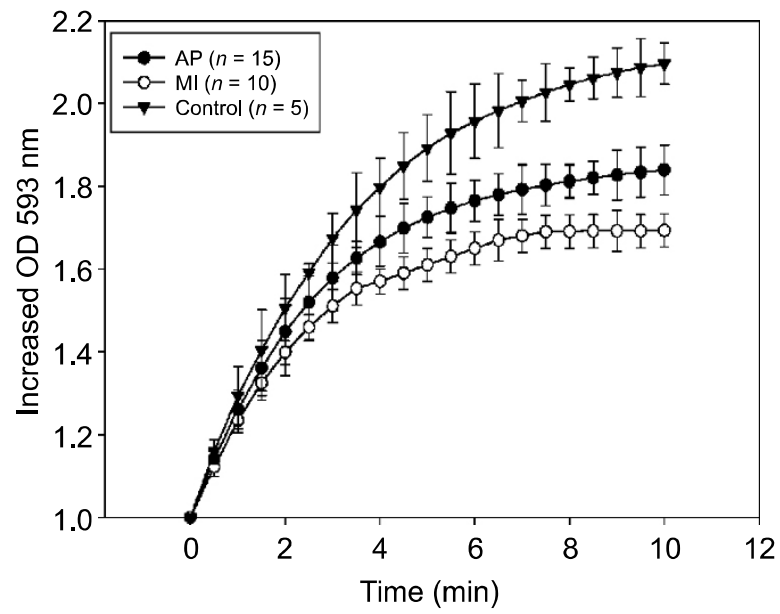

Figure 2. Comparison of the antioxidant ability based on the ferric-reducing ability of plasma (FRAP). The MI group showed the weakest reducing ability among groups, whereas the control group showed the strongest reducing ability after 10 min of incubation. that the antioxidant ability of $\mathrm{HDL}_{3}$ was almost completely absent in ACS patients. In addition, the $\mathrm{AP}$ and $\mathrm{MI}$ groups showed approximately $50 \%$ more LDL-associated $\mathrm{PLA}_{2}$ than the control group. However, $\mathrm{HDL}_{2}$-associated $\mathrm{PLA}_{2}$ activity was much lower in the AP and MI groups, being only $63 \%$ of that of the control groups. These results are in good agreement with those of a previous report in which LDL-associated $\mathrm{PLA}_{2}$ activity was found to be an independent risk factor of CAD responsible for triggering the inflammatory process (Packard et al., 2000). Additionally, there was no significant difference in the $\mathrm{HDL}_{3}-\mathrm{PLA}_{2}$ activity among all groups, indicating that $\mathrm{HDL}_{3}-\mathrm{PLA}_{2}$ activity was less effected by the onset of the disease. Taken together, the activities of antioxidant enzymes including LCAT and PON were much lower in the $\mathrm{AP}$ and $\mathrm{MI}$ group than in the control group.

\section{Ferric ion reducing ability of plasma (FRAP)}

The FRAP assay is known to be a rapid and reproducible method for determination of the molar concentration of antioxidants present in plasma in vivo (Benzie and Strain, 1996). We conducted a FRAP assay using patients' sera to compare the in vivo antioxidant effects among groups. As shown in Figure 2, the $\mathrm{Ml}$ group showed only a $69 \pm 4 \%$ increase in absorbance at $593 \mathrm{~nm}$ (A593) during 10 min of incubation, while the AP and control group showed $83 \pm 6 \%$ and $109 \pm 5 \%$ increases, respectively. This result indicates that the FRAP ability of the MI group was lower than that of the AP group, indicating the weakest antioxidant ability.
A

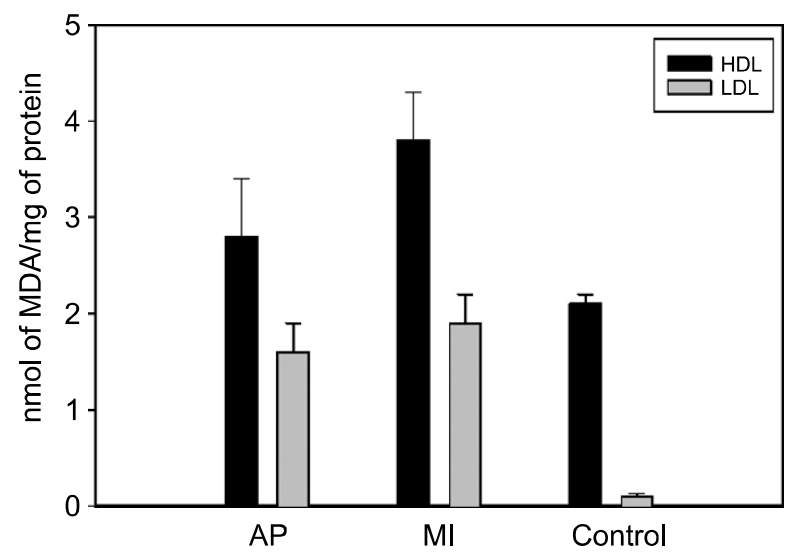

B

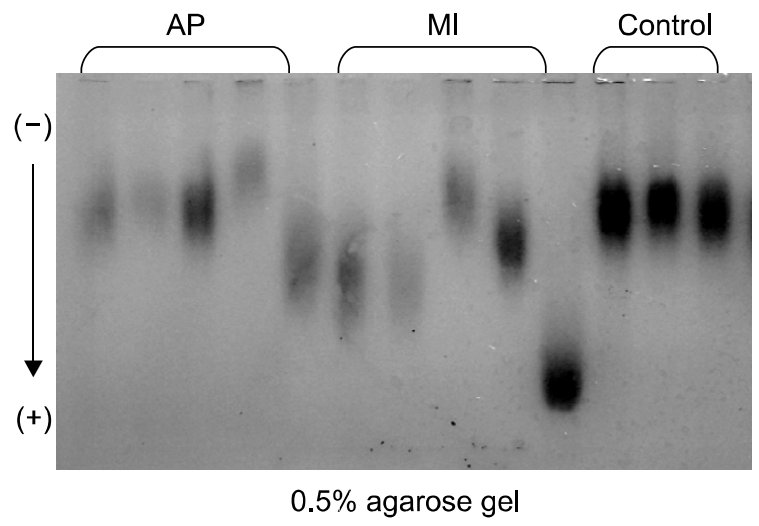

Figure 3. TBARS assay of LDL without copper mediated oxidation (panel A) compared with the malondialdehyde content and electromobility in agarose gel (panel B) for patients and controls. Ml patients showed the highest level of MDA content and the fastest electromobility on the agarose gel. Copper-mediated oxidation of $\mathrm{HDL}_{3}$ (panel A) from patients and controls. Each $\mathrm{HDL}_{3}\left(50 \mu \mathrm{l}, 2 \mathrm{mg} / \mathrm{ml}\right.$ ) was incubated with $\mathrm{CuSO}_{4}($ final $25 \mu \mathrm{M})$ for $5 \mathrm{~h}$ at $37^{\circ} \mathrm{C}$. 


\section{More oxidized LDL was detected in MI patients}

The extent of LDL oxidation among patients and control was compared. Based on the results of TBARS analysis, the LDL of $\mathrm{MI}$ and AP patients contained significantly higher levels of MDA (1.9 \pm 0.3 and $1.6 \pm 0.7 \mathrm{nmol}$, respectively) than that of the control group $(0.1 \pm 0.03 \mathrm{nmol}$ ) (Figure 3A). In addition, an electrophoretic mobility assay confirmed that the LDL fraction of $\mathrm{MI}$ and $\mathrm{AP}$ patients migrated much faster with more decayed band intensity than that of the control group (Figure 3B). Taken together, these results strongly suggest that the LDL of MI patients is more oxidized than that of AP patients, even though the LDL of AP patients had a higher TC and TG content (Table 3 ). These findings are in agreement with those of a previous report that found oxLDL levels to be significantly positively correlated with the severity of acute coronary syndromes (Ehara et al., 2001).

\section{Copper mediated oxidation of HDL}

Copper mediated oxidation was conducted with $\mathrm{HDL}_{3}$ obtained from the patient and control groups. $\mathrm{HDL}_{3}$ (2 $\mathrm{mg}$ of protein/ml) from the Ml group showed the most sensitivity to oxidation, with production of $3.8 \pm 0.5 \mathrm{nmol}$ MDA being observed in response to treatment with $25 \mu \mathrm{M}$ copper as opposed to only 2.1 $\pm 0.1 \mathrm{nmol}$ MDA being produced by the same treatment in the control group (Figure $3 \mathrm{~A}$ ). This result suggests that the antioxidant ability of $\mathrm{HDL}$ from the MI group was more impaired than that of HDL obtained from the AP group.

\section{Discussion}

Although $\mathrm{MI}$ and $\mathrm{AP}$ both have the same pathological mechanism for development, their clinical symptoms and prognosis are different. Numerous studies have suggested that there are several biomarkers for the diagnosis of $\mathrm{Ml}$; however, no unique prognostic biomarkers for early detection of $\mathrm{MI}$ or ischemic heart disease progress have been identified. Furthermore, it is difficult and inconvenient to distinguish $\mathrm{MI}$ from $\mathrm{AP}$ due to an invasive protocol. Therefore, this study was conducted to identify unique prognostic biomarkers to distinguish $\mathrm{MI}$ and $\mathrm{AP}$ in the serum and serum lipoprotein level.

Even though the number of $\mathrm{Ml}$ patients in the current study was small $(n=10)$, the findings of this study should not be underestimated because the patients were first diagnosed as MI without comorbid diseases did not take any other medication including statins. The MI patients showed typical diagnostic characters of the Asian-Pacific popula- tion, including not being obese and having normal level of TC (approx. $208 \pm 20 \mathrm{mg} / \mathrm{dl}$ ) and HDL-C (approx. $54 \pm 13 \mathrm{mg} / \mathrm{dl}$ ). Those numbers are fall in normal ranges suggested by the national cholesterol education program-adult treatment panel (NCEP-ATP) III guidelines. This indicates that simple application of the NCEP guideline might be limited in its ability to identify the risk of MI for Asian-Pacific patients. It has been speculated that there may be an abrupt increase of inflammatory markers and oxidative stress in the serum of $\mathrm{Ml}$ patients. The oxidative modification of LDL, which is considered to be a strong risk factor for atherosclerosis and ACS, occurs through the release of a proinflammatory and oxidative signal. These information are confirmed by the results of the current study, which indicated that patients in the MI group contained more oxidized LDL and increased serum IL-6 levels than patients in the other groups. In addition, the serum MPO and LPO levels were co-increased in the AP and MI group, which indicate that increased oxidative stress is a fundamental power of ACS. Serum MPO is involved in an inflammatory process that leads to the production of dysfunctional HDL through oxidative modification (Shao et al., 2006; Meuwese et al., 2007). However, it is difficult to distinguish MI patients from AP patients based on hsCRP levels because the levels are similar in both types of patients (Table 2). This suggests that hsCRP may not be a unique biomarker for the detection of $\mathrm{MI}$, although it is a good diagnostic marker for detection of CAD. A number of population based study have suggested that there is a strong consistency in the relationship between ACS and inflammatory markers, such as hsCRP (Tuomisto et al., 2006), IL-6, and lipoprotein associated phospholipase $\mathrm{A}_{2}$ (Ballantyne et al., 2004). These markers have been elevated in CVD patients and frequently precede to the development of ACS. Our current study also supports the same increase of the markers; serum IL-6 level, LDL-PLA 2 activity, and white blood cell number were significantly increased in AP and MI group.

A low HDL-C level is the most common lipid abnormality observed in families with premature CHD (Genest et al., 1992). However, in the current study, the MI group was found to have a slightly higher level of serum HDL-C than the AP group, even though $\mathrm{MI}$ patients were found to have a lower percentage of HDL-C per TC than AP patients (Table 3 ). This result suggests that a simple comparison of serum HDL-C levels might not be useful for the prediction of MI. More importantly, $\mathrm{HDL}_{2}-\mathrm{C}$ level was lower and HDL-TG level was higher in MI patients than that of AP patients, 
indicating that the lipid composition of $\mathrm{HDL}_{2}$ might be useful for evaluating the risk of MI. Similarly, we recently reported that there is a direct relationship between an increase in the levels of apoC-III, serum TG, acute inflammatory process markers such as IL-6, and a decrease of HDL-C in the oliguric phase of hemorrhagic fever renal syndrome (HFRS) patients (Cho et al., 2008). In addition, Hartford et al. (2007) reported that CRP, IL-6, and sPLA2 are intercorrelated in patients with ACS, whereas iCAM-1 appears to respond differently to acute coronary events. Recently Suzuki et al. (2008) reported that elevation of matrix metalloproteinases and IL- 6 are involved in the instability of vulnerable plaque associated with the induction of myocardial infarction. Taken together, these results strongly indicate that a decrease in HDL-C and an increase in HDL-TG are linked to a malfunction of $\mathrm{HDL}$, which is responsible for the antioxidant power against oxidation of LDL.

Many studies have suggested that the TG-rich lipoproteins are proatherogenic (McBride, 2007; Libby, 2007). The presence of increased TG in the lipoprotein is in good agreement with the results of previous studies that indicated that TG levels are an important and independent predictor of $\mathrm{CHD}$ and stroke risk in the Asia-Pacific region (Asia pacific cohort studies collaboration, 2004). Furthermore, the serum TG was accumulated more in the $\mathrm{LDL}$ and $\mathrm{HDL}_{2}$ fractions than in the VLDL fraction, which is similar to the results of previous studies that have found a strong and consistent association of hypertriglyceridemia with a dense LDL fraction (Austin et al., 1988; Campos et al., 1992). In this study, MI patients were found to have higher level of apoC-III, CETP, and TG-enriched LDL that was more oxidized than AP group.

Overall, the results of this study revealed that MI patients showed significantly increased serum IL-6 and TG levels and decreased serum apoA-I levels when compared to AP patients. Levels of the TG, apoC-III and CETP in the LDL and HDL fractions of MI patients were increased, whereas the level of HDL-C was decreased. These results strongly suggest that the composition of lipoprotein is altered in $\mathrm{Ml}$ patients with more increase of inflammatory factors, even though the levels of oxidative species were similar among AP and MI patients.

\section{Methods}

\section{Patients and controls}

Stable AP patients $(n=17)$ were selected using the following criteria: the presence of chest or arm discomfort that is rarely described as pain, but is reproducibly associated with physical exertion or stress and relieved within 5 to 10 min of rest and/or administration of sublingual nitroglycerin. The diagnosis was confirmed with treadmill exercise test and coronary angiography in all patients.

MI patients $(n=10)$ were defined as individuals that exhibited angina pectoris or equivalent ischemic discomfort and at least one of the following three features: [1] symptoms occur at rest (or with minimal exertion) and usually last $>10 \mathrm{~min}$, [2] symptoms are severe and of new onset, and/or [3] symptoms exhibit a crescendo pattern (i.e., becoming distinctly more severe, prolonged, or frequent with time) (Kasper et al., 2005). In addition, the presence of any one of the following criteria when there was evidence of myocardial necrosis in a clinical setting consistent with myocardial ischemia was diagnosed as myocardial infarction: [1] Electrocardiogram (ECG) changes indicative of new ischemia (new ST-T changes or new left bundle branch block), [2] development of pathologic $Q$ waves in the ECG, and [3] imaging evidence of new loss of viable myocardium or new regional wall motion abnormality (Thygesen et al., 2007).

All AP and MI patients were first diagnosed, and patients with diabetes, history of familial dyslipidemia and previous use of medications including statin, were excluded from the analysis. Percutaneous coronary interventions were performed at the physician's discretion if needed, as indicated in the guideline. Patients did not take any medication besides statin prior to hospitalization.

Age and gender matched reference subjects $(n=7)$ were recruited from healthy volunteers who visited Health Center of Yeungnam University Hospital (Daegu, Korea) for regular health check up. They had unremarkable medical records without history of endocronological disorder.

Informed consent was obtained from all patients and reference individuals (control group) prior to enrollment in the study and the institutional review board at the Medical Center of Yeungnam University approved the protocol.

\section{Plasma and lipoprotein}

Blood was drawn on overnight fasting state in AP patients, and blood sampling was done in the emergency room immediately after the diagnosis of MI was confirmed by a detailed clinical history, ECG and/or serologic tests in case of $\mathrm{Ml}$ patients. Blood was collected using a vacutainer (BD sciences, Franklin Lakes, NJ) containing EDTA (final 1 $\mathrm{mM}$ ). Plasma was isolated by low speed centrifugation and stored at $-80^{\circ} \mathrm{C}$ until analysis.

VLDL $(\mathrm{d}<1.019 \mathrm{~g} / \mathrm{ml})$, LDL $(1.019<\mathrm{d}<1.063), \mathrm{HDL}_{2}$ $(1.063<\mathrm{d}<1.125)$, and $\mathrm{HDL}_{3}(1.125<\mathrm{d}<1.225)$ were isolated from individual patient and control serum via sequential ultracentrifugation, with the density being appropriately adjusted by the addition of $\mathrm{NaCl}$ and $\mathrm{NaBr}$ in accordance with standard protocols. Samples were centrifuged for $24 \mathrm{~h}$ at $10^{\circ} \mathrm{C}$ at $100,000 \mathrm{~g}$ using a Himac CP-90 $\alpha$ (Hitachi, Tokyo, Japan) at the Instrumental Analysis Center at Yeungnam University.

\section{Biochemical analysis}

Blood parameters, lipids, and glucose concentrations were 
determined using an automatic blood analyzer (Chemistry analyzer AU4500 Olympus, Tokyo, Japan). For each of the lipoproteins (VLDL, LDL, $\mathrm{HDL}_{2}, \mathrm{HDL}_{3}$ ) which was purified individually, total cholesterol (TC) and triglyceride (TG) measurements were obtained using commercially available kits (cholesterol, T-CHO; triglyceride, Cleantech TS-S, Wako Pure Chemical, Osaka, Japan). The protein concentrations of lipoprotein were determined via Lowry protein assay, as modified by Markwell et al. (1978) and using Bradford assay reagent (BioRad, Seoul, Korea) with BSA as a standard. The blood levels of the MPO were determined using an ELISA kit that was obtained from Immunology Consultants Lab (Cat \# E-80PX, Newberg, OR). Serum lipid hydroperoxide (LPO) was determined colorimetrically using a commercial kit (Cat\# 437639, Calbiochem, San Diego, CA) in accordance with the manufacturer's suggestions.

\section{Ferric reducing ability of plasma assay}

The ferric reducing ability of plasma (FRAP) was determined using the method described by Benzie and Strain (1996). Briefly, the FRAP reagents were freshly prepared by mixing $25 \mathrm{ml}$ of $0.2 \mathrm{M}$ acetate buffer ( $\mathrm{pH} 3.6), 2.5 \mathrm{ml}$ of

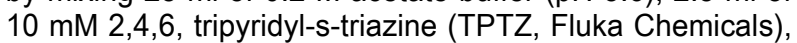
and $2.5 \mathrm{ml}$ of $20 \mathrm{mM} \mathrm{FeCl}_{3} 6 \mathrm{H}_{2} \mathrm{O}$. The antioxidant activities of the serum were then estimated by measuring the increase in absorbance induced by the generated ferrous ions. The freshly prepared FRAP reagent $(300 \mu \mathrm{l})$ was mixed with equally diluted serum $(20 \mathrm{mg} / \mathrm{ml}, 10 \mu \mathrm{l})$, after which the ferric reducing ability was determined by measuring the absorbance at $593 \mathrm{~nm}$ every $20 \mathrm{~s}$ over a 10 min period at $25^{\circ} \mathrm{C}$ using a DU800 spectrophotometer (Beckman Coulter, Fullerton, CA) equipped with a MultiTemp III thermocirculator (Amersham, Uppsala, Sweden).

\section{Cholesteryl ester conversion assay}

Cholesteryl ester conversion was conducted via lecithin: cholesterol acyltransferase (LCAT) assays as previously described (Han et al., 2005). Serum $(50 \mu \mathrm{l})$ or $\mathrm{HDL}$ fractions $(28 \mu \mathrm{g}$ of protein in $30 \mu \mathrm{L})$ were utilized as the enzyme source. ApoA-I-rHDL containing radiolabeled cholesterol $\left(1 \mu \mathrm{Ci}\right.$ of $\left[{ }^{14} \mathrm{C}\right]-4$-cholesterol/69 $\mu \mathrm{g}$ of cholesterol/ $1 \mathrm{mg}$ of apoA-I) was employed as a substrate, and the apoA-I was then expressed using an $E$. coli expression system as described previously (Cho et al., 2006). Discoidal rHDL was prepared via the sodium cholate dialysis method using initial molar ratios of palmitoyloleoyl phosphatidylcholine (POPC)-cholesterol-apoA-I-sodium cholate at a ratio of 95:5:1:150 (wt/wt/wt/wt).

The reaction was initiated via the addition of individual serum, and the mixture was then incubated for $1 \mathrm{~h}$ at $37^{\circ} \mathrm{C}$. Next, the esterified cholesterol and free cholesterol were separated via TLC, and the activity was expressed as the $\%$ conversion rate of cholesteryl ester from free cholesterol.

\section{Paraoxonase assay}

Paraoxonase-1 (PON-1) activity toward paraoxon was determined by evaluating the hydrolysis of paraoxon into p-nitrophenol and diethylphosphate, which was catalyzed by the enzyme (Eckerson et al., 1983). PON-1 activity was then determined by measuring the initial velocity of $p$-nitrophenol production at $37^{\circ} \mathrm{C}$, as determined by measuring the absorbance at $405 \mathrm{~nm}$ (Microplate reader, Bio-Rad model 680). To accomplish this, an equal amount of serum $(10 \mu \mathrm{l})$ was added to $200 \mu \mathrm{l}$ of substrate (paraoxon-ethyl, Sigma D-9286)-containing solution (90 $\mathrm{mM}$ Tris- $\mathrm{HCl} / 3.6 \mathrm{mM} \mathrm{NaCl} / 2 \mathrm{mM} \mathrm{CaCl}$, $\mathrm{pH}$ 8.5). The PON-1 activity of $1 \mathrm{U} / \mathrm{L}$ was defined as $1 \mu \mathrm{mol}$ of $p$ nitrophenol formed per minute. The molar extinction coefficient of $p$-nitrophenol was $17,000 \mathrm{M}^{-1}, \mathrm{~cm}^{-1}$.

\section{Cholesteryl ester transfer assay}

An rHDL containing apoA-I and cholesteryl oleate was synthesized in accordance with the method described by Cho et al. (1998) using trace amounts of $\left[{ }^{3} \mathrm{H}\right]$-cholesteryl oleate (GE healthcare, TRK886, $3.5 \mu \mathrm{Ci} / \mathrm{mg}$ of apoA-I). Next, to facilitate separation from the CE-acceptor, the rHDL was immobilized using a CNBr-activated Sepharose 4B resin (Amersham Biosciences, Uppsala, Sweden) in accordance with the manufacturer's instructions. The CE-transfer reaction was allowed in $300 \mu$ reaction mixtures that contained each of the serum samples $(20 \mu \mathrm{l})$ as a CETP source and rHDL-agarose $(50 \mu \mathrm{l}, 0.25 \mathrm{mg} / \mathrm{ml})$ and human LDL (50 $\mu \mathrm{l}, 0.25 \mathrm{mg} / \mathrm{ml})$ as a CE-donor and $\mathrm{CE}$-acceptor, respectively. After incubation at $37^{\circ} \mathrm{C}$, the reaction was halted via brief centrifugation $(10,000 \mathrm{~g})$ for 3 $\min$ at $4^{\circ} \mathrm{C}$. The supernatant $(150 \mu \mathrm{l})$ was then subjected to scintillation counting, and the percentage transfer of $\left[{ }^{3} \mathrm{H}\right]-\mathrm{CE}$ from rHDL to LDL was calculated.

\section{Lipoprotein-associated phospholipase 2 assay}

The individual lipoprotein fraction $(10 \mu \mathrm{l}, 20 \mu \mathrm{g})$ was used as an enzyme source for the $\mathrm{PLA}_{2}$ reaction, with an Lp-PLA ${ }_{2}$ assay being conducted according to the method described by Boyd et al. (2000). Briefly, $\left[{ }^{3} \mathrm{H}\right]$-platelet activating factor (Hexadecyl-2-acetyl-sn-glyceryl-3-phosphorylcholine, Perkin-Elmer, NET910, $0.1 \mathrm{mCi} / \mathrm{ml}$ ) and 1-O-hexadecyl-2-acetyl-sn-glycero-3-phosphocholine was used as a substrate for the reaction. Substrate solution containing $10 \mu \mathrm{l}$ of the $\left[{ }^{3} \mathrm{H}\right]-\operatorname{PAF}(1 \mu \mathrm{Ci}, 50 \mu \mathrm{M})$ and $12 \mu \mathrm{M}$ of cold PAF was incubated using each lipoprotein solution as an Lp-PLA 2 source for $30 \mathrm{~min}$. The reaction was then stopped by vortexing the solutions with $600 \mu \mathrm{l}$ of $\mathrm{CHCl}_{3}$ : $\mathrm{Me}-\mathrm{OH}(2: 1, \mathrm{v} / \mathrm{v})$, after which the aqueous layer $(150 \mu \mathrm{l})$ was removed. The aqueous layer was then vortexed again with $\mathrm{CHCl}_{3}$, after which it was centrifuged and the upper phase was used for scintillation counting.

\section{ELISA, western blot analysis, and electrophoresis}

For sandwich ELISA, diluted primary antibody (1:2,000 or $1: 4,000)$ was coated onto a 96 well plate (Nunc Maxisorp 439454) overnight at $4^{\circ} \mathrm{C}$. As primary antibodies, apoA-I antibody (Abcam, ab7613) and CETP antibody (ab19012) were purchased from Abcam (Cambridge, UK), and apoC-III antibody was obtained from Chemicon (Cat\# AB821, Temecula, CA). HRP-conjugated apoA-I antibody 
(ab20784) and HRP-apoC-III antibody (ab27624) were purchased from Abcam and used as secondary antibodies. A substrate reagent pack (R\&D system, DY999) was used for color development.

The apolipoprotein/lipoprotein compositions were compared via SDS-PAGE with an equal amount of protein loading, and the expressional level of apolipoprotein was analyzed via Western blot analysis. In order to compare the electromobility of patient and control samples, the migration of each lipoprotein (LDL, $\mathrm{HDL}_{2}$, and $\mathrm{HDL}_{3}$ ) was evaluated by agarose electrophoresis. The gels were then dried and stained with $0.125 \%$ Coomassie brilliant blue, after which the relative band intensities were compared via band scanning using a Gel Doc XR (Bio-Rad, Hercules, $\mathrm{CA})$ with Quantity One software, version 4.5.2.

\section{Data analysis}

All data were expressed as the mean \pm S.D. The data were evaluated via one-way analysis of variance (ANOVA) using an SPSS program (version 12.0, Chicago, IL), and the differences between the means were assessed using Duncan's multiple-range test. Statistical significance was defined as $P<0.05$.

\section{Acknowledgements}

This work was supported by KOSEF, through the Agingassociated Vascular Disease Research Center at Yeungnam University (R13-2005-005-01003-0 (2007)).

\section{References}

Asia pacific cohort studies collaboration. Serum triglycerides as a risk factor for cardiovascular diseases in the asia-pacific region. Circulation 2004;110:2678-86

Austin MA, Breslow JL, Hennekens CH, Buring JE, Willett WC, Krauss RM. Low-density lipoprotein subclass patterns and risk of myocardial infarction. J Am Med Assoc 1988; 260:1917-21

Ballantyne CM, Hoogeveen RC, Bang $\mathrm{H}$, Coresh J, Folsom AR, Heiss G, Sharrett AR. Lipoprotein-Associated Phospholipase $\mathrm{A}_{2}$, High-Sensitivity C-Reactive Protein, and Risk for Incident Coronary Heart Disease in Middle-Aged Men and Women in the Atherosclerosis Risk in Communities (ARIC) Study. Circulation 2004;109:837-42

Benzie IF, Strain JJ. The ferric reducing ability of plasma (FRAP) as a measure of "antioxidant power": the FRAP assay. Anal Biochem 1996;239:70-6

Boyd HF, Fell SCM, Flynn ST, Hickey DMB, Ife RJ, Leach CA, Macphee $\mathrm{CH}$, Milliner KJ, Moores KE, Pinto IL, Porter RA, Rawlings DA, Smith SA, Stansfield IG, Tew DG, Theobald CJ, Whittaker CM. N-1 substituted pyrimidin-4-ones: novel, orally active inhibitors of lipoprotein-associated phospholipase $A_{2}$. Bioorg Med Chem Lett 2000;10:2557-61

Campos H, Genest JJ, Blijlevens E, McNamara JR, Jenner JL, Ordovas JM, Wilson PWF, Shaefer EJ. Low density lipoprotein particle size and coronary artery disease. Arterioscler Thromb 1992;12:187-95
Cho KH, Lee JY, Choi MS, Cho JM, Lim JS, Park YB. A peptide from hog plasma that inhibits human cholesteryl ester transfer protein. Biochim Biophys Acta 1998;1391:133-44

Cho KH, Park SH, Han JM, Kim HC, Choi YK, Choi I. ApoA-I mutants V156K and R173C promote anti-inflammatory function and antioxidant activities. Eur J Clin Invest 2006; 36:875-82

Cho KH, Park JE, Kim YO, Choi I, Kim JJ, Kim JR. The function, composition, and particle size of high-density lipoprotein were severely impaired in an oliguric phase of hemorrhagic fever with renal syndrome. Clin Biochem 2008;41:56-64

Eckerson HW, Wyte CM, La Du BN. The human serum paraoxonase/arylesterase polymorphism. Am J Hum Genet 1983;35:1126-38

Ehara S, Ueda M, Naruko T, Haze K, Itoh A, Otsuka M, Komatsu $\mathrm{R}$, Matsuo $\mathrm{T}$, Itabe $\mathrm{H}$, Takano $\mathrm{T}$, Tsukamoto $\mathrm{Y}$, Yoshiyama M, Takeuchi K, Yoshikawa J, Becker AE. Elevated levels of oxidized low density lipoprotein show a positive relationship with the severity of acute coronary syndromes. Circulation 2001;103:1955-60

Genest JJ, Martin-Munley SS, McNamara JR, Ordovas JM, Jenner J, Myers RH, Silberman SR, Wilson PWF, Salem DN, Schaefer EJ. Famillial lipoprotein disorders in patients with premature coronary artery disease. Circulation 1992;85: 2025-33

Han JM, Jeong TS, Lee WS, Choi I, Cho KH. Structural and functional properties of $\mathrm{V} 156 \mathrm{~K}$ and $\mathrm{A} 158 \mathrm{E}$ mutants of apolipoprotein A-I in the lipid-free and lipid-bound states. J Lipid Res 2005;46:589-96

Hartford M, Wiklund O, Hullten LM, Persson A, Karlsson T, Herlitz J, Caidahl K. C reactive protein, interleukin-6, secretory phospholipase A group IIA and intercellular adhesion molecule- 1 in the prediction of late outcome events after acute coronary syndromes. J Intern Med 2007;262: 526-36

Hokanson JE, Austin MA. Plasma triglyceride level is a risk factor for cardiovascular disease independent of highdensity lipoprotein cholesterol level. J Cardiovasc Risk 1996;3:213-9

Jaffe AS, Ravkilde J, Roberts R, Naslund U, Apple FS, Galvani M, Katus H. It's time for a change to a troponin standard. Circulation 2000;102:1216-20

Kasper DL, Braunwald E, Fauci AS, Hauser SL, Longo DL, Jameson JL. Harrison's Principles of Internal Medicine, 16th Ed, McGraw-Hill, 2005, p.1444

Libby P. Fat fuels the flame triglyceride-rich lipoproteins and arterial inflammation. Circulation 2007;100:299-301

Markwell MAK, Haas SM, Bieber LL, Tolbert NE. A modification of the Lowry procedure to simplify protein determination in membrane and lipoprotein samples. Anal Biochem 1978;87:206-10

McBride PE. Triglycerides and risk for coronary heart disease. J Am Med Assoc 2007;298:336-8

Meuwese MC, Stroes ESG, Hazen SL, Van Miert JN, Keivenhoven JA, Schaub RG, Wareham NJ, Luben R, 
Kastelein JJP, Khaw, KT, Boekholdt M. Serum myeloperoxidase levels are associated with the future risk of coronary artery disease in apparently healthy individuals. J Am Coll Cardiol 2007;50:159-65

Packard CJ, O'Reilly DSJ, Caslake MJ, McMahon AD, Ford I, Cooney J, Macphee CH, Suckling KE, Krishna M, Wilkinson FE, Rumley A, Lowe GDO. Lipoprotein-associated phospholipase $A 2$ as an independent predictor of coronary heart disease. West of Scotland Coronary Prevention Study Group. N Engl J Med 2000;343:1148-55

Pahor M, Elam MB, Garrison RJ, Kritchevsky SB, Applegate WB. Emerging noninvasive biochemical measures to predict cardiovascular risk. Arch Intern Med 1999;159:237-45

Rosamond W, Flegal K, Friday G, Furie K, Go A, Greenlund K. Heart disease and stroke statistics-2007 Update. Circulation 2007;115e:e69-e171

Sacks FM, Alaupovic P, Moye LA, Cole TG, Sussex B, Stampfer MJ, Pfeffer MA, Braunwald E. VLDL, aolipoprotein $\mathrm{B}, \mathrm{CIII}$, and $\mathrm{E}$, and risk of recurrent coronary events in the cholesterol and recurrent events trial. Circulation 2000; 102:1886-92

Shao B, Oda MN, Oram JF, Heinecke JW. Myeloperoxidase:an inflammatory enzyme for generating dysfunc- tional high density lipoprotein. Curr Opin Cardiol 2006;21: 322-8

Suzuki H, Kusuyama T, Sato R, Yokota Y, Tsunoda F, Sato T, Shoji M, Iso Y, Koba S, Katagiri T. Elevation of matrix metalloproteinases and interleukin- 6 in the culprit coronary artery of myocardial infarction. Eur J Clin Invest 2008;38: 166-73

Thygesen K, Alpert JS, White HD, Jaffe AS, Apple FS, Galvani M. Universal definition of myocardial infarction. Circulation 2007;116:2634-53

Tsimikas S, Willerson JT, Ridker, PM. C-Reactive protein and other emerging blood biomarkers to optimize risk stratification of vulnerable patients. J Am Coll Cardiol 2006; 47:C19-31

Tuomisto K, Jousilahti P, Sundvall J, Pajunen P, Salomaa V. C-reactive protein, interleukin- 6 and tumor necrosis factor alpha as predictors of incident coronary and cardiovascular events and total mortality. A population-based, prospective study. Thromb Haemost 2006;95:511-8

Walldius $G$, Jungner $I$. Is there a better marker of cardiovascular risk than LDL cholesterol? Apolipoproteins B and A-I-new risk factors and targets for therapy. Nutr Metab Cardiovasc Dis 2007; 17:565-71 